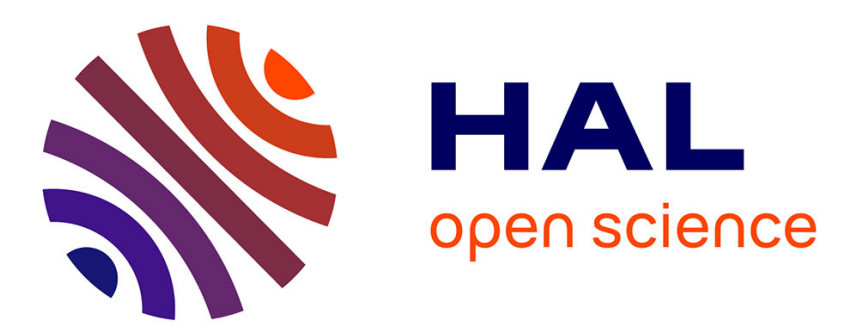

\title{
Nonsymmetrically Substituted Uranyl-Salophen Receptors: New Opportunities for Molecular Recognition and Catalysis
}

\author{
Antonella Dalla Cort, Luca Schiaffino, Chiara Pasquini
}

\section{To cite this version:}

Antonella Dalla Cort, Luca Schiaffino, Chiara Pasquini. Nonsymmetrically Substituted UranylSalophen Receptors: New Opportunities for Molecular Recognition and Catalysis. Supramolecular Chemistry, 2007, 19 (01-02), pp.79-87. 10.1080/10610270600977714 . hal-00513490

\author{
HAL Id: hal-00513490 \\ https://hal.science/hal-00513490
}

Submitted on 1 Sep 2010

HAL is a multi-disciplinary open access archive for the deposit and dissemination of scientific research documents, whether they are published or not. The documents may come from teaching and research institutions in France or abroad, or from public or private research centers.
L'archive ouverte pluridisciplinaire HAL, est destinée au dépôt et à la diffusion de documents scientifiques de niveau recherche, publiés ou non, émanant des établissements d'enseignement et de recherche français ou étrangers, des laboratoires publics ou privés. 


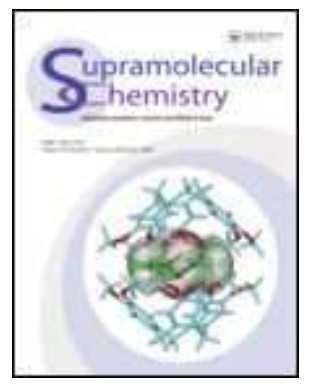

\section{Nonsymmetrically Substituted Uranyl-Salophen Receptors: New Opportunities for Molecular Recognition and Catalysis}

\begin{tabular}{|r|l|}
\hline Journal: & Supramolecular Chemistry \\
\hline Manuscript ID: & GSCH-2006-0031.R1 \\
\hline Manuscript Type: & Special Issue Paper \\
\hline Date Submitted by the \\
Author: & 16 -Aug-2006 \\
\hline Keywords: List of Authors: & $\begin{array}{l}\text { Dalla Cort, Antonella; Università di Roma La Sapienza, Dept. of } \\
\text { Chemistry } \\
\text { Schiaffino, Luca; Università di Roma La Sapienza, Dept. of } \\
\text { Chemistry } \\
\text { Pasquini, Chiara; Università di Roma La Sapienza, Dept. of } \\
\text { Chemistry }\end{array}$ \\
\hline & \begin{tabular}{l} 
Nomplexes, Uranyl ion, Uranyl ion, Inherent chirality \\
\hline
\end{tabular} \\
\hline
\end{tabular}

\section{S) ScholaroNE \\ Manuscript Central}


Nonsymmetrically Substituted Uranyl-Salophen Receptors: New Opportunities for Molecular Recognition and Catalysis

\author{
Antonella Dalla Cort*, Chiara Pasquini and Luca Schiaffino \\ Dipartimento di Chimica and IMC-CNR, Università La Sapienza, \\ Box 34 - Roma 62, 00185 Roma, Italy \\ E-mail: Antonella.dallacort@uniromal.it
}

\begin{abstract}
This short review highlights recent results in the chemistry of nonsymmetrically substituted uranyl-salophen complexes with specific reference to their synthesis and properties. Their use as receptors and catalysts is also emphasized. The possibility of modulating their structure within wide limits by choosing the proper substituted aldehydes and/or ketones as starting materials, coupled with their inherent chirality offers new appealing opportunities for their applications.
\end{abstract}

Running Title: Nonsymmetrically Substituted Uranyl-Salophen Complexes

Keywords: Non symmetrical salophen ligands, Uranyl tetradentate Schiff base complexes, Uranyl ion, Inherent chirality 
Salophens are one of the oldest and most popular class of ligands in coordination chemistry because of their versatility and easy synthetic availability. ${ }^{1}$ They are diimino tetradentate Schiff bases derived from the condensation of 1,2-phenylenediamine, or of its derivatives, with two equivalents of salicylaldehyde. A large number of synthetic routes to ortho-substituted phenols and to the corresponding ortho salicylaldehydes gives access to a large variety of structures with subtle variations in the steric and electronic configuration. For these reasons they have been extensively used to coordinate transition and main group metals.

In their dianionic form 1, these ligands possess two covalent and two coordinative binding sites located in a planar array. This arrangement allows the equatorial coordination of transition metals, the two apical positions of which can be further occupied by ancillary ligands, in an arrangement similar to that of porphyrins. Such complexes have found a host of applications in enantioselective catalysis, ${ }^{2}$ in enzyme modelling, ${ }^{3}$ in liquid crystals, ${ }^{4}$ and in building up abiotic electrochemically responsive foldamers $^{5}$ and new materials exhibiting non linear optical properties. ${ }^{6}$

Insert structures $\mathbf{1}$ and $\mathbf{2}$

Among the transition metals that form robust complexes with salophen ligands there is the hexavalent uranyl ion, $\mathrm{UO}_{2}{ }^{+2} \cdot$ The coordination chemistry of this cation has lately gained increasing attention thanks to several reasons, mainly the great interest in the extraction of uranium from sea waters and the search for selective removal of it from soil, ground water, and even from human tissues and body fluids by means of a number of chemical complexing agents that can form easily releasable low-molecular weight 
chelates. ${ }^{8}$ The $\mathrm{UO}_{2}{ }^{+2}$ cation has a well known preference for pentagonal bipyramidal coordination, with the two oxygens in the apical positions. After accommodation of the four donor groups of the salophen ligand as in $\mathbf{2}$, a fifth equatorial site is still available to coordination with an additional group, ${ }^{9}$ such as an anion ${ }^{10}$ or a neutral molecule ${ }^{11}$ endowed with a hard donor site, while in the absence of such guests, the fifth equatorial binding site is generally occupied by a solvent molecule. ${ }^{12}$ For these reasons these electrically neutral complexes have found several applications as receptors, ${ }^{13}$ catalysts, ${ }^{14}$ carriers, ${ }^{15}$ and sensors. ${ }^{16}$ In this context our recent finding that nonsymmetrically substituted uranyl-salophen complexes are inherently chiral and exist as a pair of enantiomers ${ }^{17}$ has raised interest toward a number of appealing potential applications concerning enantioselective recognition and asymmetric catalysis. In this short review we will highlight the most recent results on the synthesis of nonsymmetrically substituted uranyl-salophen complexes and on their properties.

Synthesis. As already mentioned, symmetrical metal-salophen complexes are easily prepared by condensation of the corresponding phenylenediamine with two equivalents of the proper substituted salicylaldehyde in a one-pot reaction that generally uses methanol or ethanol as a solvent. It is easy to understand that the synthetic approach toward non symmetrical metal-salophen complexes cannot be so straightforward. In the literature there is a certain number of examples dealing with the synthesis of nonsymmetrical salen complexes, ${ }^{18,19,20,21,22}$ while fewer are those concerning also salophen derivatives..$^{23,24}$ 
There is more than one possibility to break the symmetry of the complex. We can start from a nonsymmetrically substituted 1,2-phenylendiamine (A in Figure 1); from two different aromatic carbonyl derivatives (B in Figure 1), one of which is not an aldehyde, or from two different salicylaldehydes (C in Figure 1). Examples of the first type are reported by Kleij et al. ${ }^{24}$ for the preparation of metallo(II)-salophen complexes, $M=\mathrm{Zn}$, $\mathrm{Ni}$. In this case the aldehyde, the phenylenediamine derivative, and the corresponding metal salt $\mathrm{M}(\mathrm{OAc})_{2} \cdot n \mathrm{H}_{2} \mathrm{O}(\mathrm{M}=\mathrm{Zn}: \mathrm{n}=2 ; \mathrm{M}=\mathrm{Ni}: \mathrm{n}=4)$ are mixed in the appropriate stoichiometry in methanol at room temperature. The isolation of the product is obtained by simple filtration of the reaction mixture, see Scheme 1 .

\section{Insert Scheme 1}

According to Bogheaei and Mohebi, ${ }^{23}$ complexes of types $\mathrm{B}$ and $\mathrm{C}$ can be obtained by a two step procedure involving first the preparation of the monoimine from salicylaldehyde and phenylenediamine in a 1:1.3 molar ratio in ethanol at low temperature, $5-10{ }^{\circ} \mathrm{C}$, with subsequent removal of the excess of diamine by extraction in benzene. The reaction of this half unit with 2-hydroxyacetophenone in degassed, anhydrous ethanol gives $\mathbf{3}$ in 71\% yield (Scheme 2). A number of examples are reported by the authors. In their case the complex with vanadium is obtained by adding to a hot solution of 3 in mixed solvent $\left(\mathrm{CHCl}_{3} / \mathrm{EtOH} / \mathrm{MeOH}, 10 / 15 / 10\right)$ a hot solution of $\mathrm{VO}$ (acac) in methanol. After 30 min reflux, concentration of the mixture leads to the isolation of the corresponding nonsymmetrical vanadyl Schiff base complex in a $83 \%$ yield. 


\section{Insert Scheme 2}

Another possibility is a metal-assisted synthesis of the complex. To a 1:1 solution of the half unit and of the metal salt in ethanol is added an equimolar amount of the appropriate acetophenone. This leads, after reflux and cooling, to the isolation of the desired product by filtration. An example of the use of this two step procedure for the synthesis of complexes of type $\mathrm{C}$ has been reported by Kleij et al. ${ }^{24}$ The authors underline the importance of the choice for an excess of phenylenediamine in the selective isolation of monoimine products, but we have obtained the pure monoimine also from strictly equimolar mixtures of the two reactants.

In the synthesis of nonsymmetrical salen-type ligands using two different salicylaldehyde moieties, Nguyen and Campbell ${ }^{20}$ adopt the strategy of protecting one amino group of the ethylenediamine prior to condensation with the first salicylaldehyde. They prepare the mono-ammonium salt by treatment of the diamine with hydrogen chloride in anhydrous ether. The salt is added to one equivalent of salicylaldehyde, producing the corresponding monoimino ammonium salt in high yield. This is then added to one equivalent of a second salicylaldehyde derivative in the presence of triethylamine to produce the desired product. Also Gilheany et $\mathrm{al}^{22}$ tried to follow this strategy of trapping the mono-Schiff base, but the poor results obtained prompted them to continue with chromatographic separation of reaction mixtures in which all the three possible combination of the reagents are present. As far as we know, no similar procedure has been adopted to synthesize nonsymmetrical metal salophen complexes. In our own experience, in the case of uranyl-salophen complexes the two step procedure invariably leads to a mixture of the three statistical products. This led us to conclude 
that the best way to pure nonsymmetrical uranyl complexes of type $\mathrm{C}$ is the chromatographic separation of the three products obtained by the one-pot reaction of phenylenediamine, salicylaldehyde, and an ortho substituted salicylaldehyde in a 1:1:1 ratio with 1 mol equiv. of $\mathrm{UO}_{2}(\mathrm{OAc})_{2} \bullet 4 \mathrm{H}_{2} \mathrm{O}$ in methanol at room temperature. Since we have already checked that preformed nonsymmetrical uranyl salophen complexes do not equilibrate with the two corresponding symmetrical compounds in the presence of 2 mol equiv. of acetic acid, ${ }^{14 c}$ we believe that our failures in the two step synthesis are a consequence of the intrinsic lability toward hydrolysis of the preformed monoimine in the presence of the Lewis acidic uranyl dication before uranyl-salophen complexes are formed.

The only case in which we succeeded in using the two step procedure was the synthesis of compound 4. Mixing 1,2-phenylenediamine, 3-isopropylsalicylaldehyde, 2-hydroxybenzophenone, and uranyl acetate according to the one-pot procedure for the metal complex proved to be unsuccessful as 2-hydroxybenzophenone did not react under these conditions and only the symmetrical uranyl-salophen complex $\mathbf{5}$ was recovered. In this case 1,2-phenylenediamine and 2-hydroxybenzophenone were condensed in toluene with use of a Dean Stark apparatus to obtain the monoimine 6 that was subsequently reacted with 3-isopropylsalicylaldehyde and uranyl acetate in methanol to get the desired product without formation of the unwanted symmetrical compounds. These findings can be rationalised by taking into account the lower reactivity of 2-hydroxybenzophenone and of the corresponding monoimine $\mathbf{6}$ toward nucleophilic attack, that prevents both the reaction of 2-hydroxybenzophenone in the one pot synthesis and the hydrolysis of the monoimine in the second stage of the two step procedure. 
Insert structures 4, 5, 6

\section{Chirality in nonsymmetrically substituted uranyl-salophen complexes. An} important feature of uranyl-salophen complexes is that, due to the large ionic radius of the uranium atom in the uranyl dication, the salophen ligand cannot assume a planar geometry and the resulting complex ends up being severely puckered. This is clearly shown by available X-ray crystallographic data ${ }^{12,25}$ and well illustrated by the computer calculated structure of the uranyl-salophen unit, Figure 2. In nonsymmetrically substituted uranyl-salophen derivatives this feature clearly leads to the loss of any symmetry element and consequently makes these compounds inherently chiral. To our surprise, no one had ever made the consideration that nonsymmetrically substituted uranyl-salophen complexes should exist as pairs of enantiomers, and no experimental evidences were reported concerning this possibility.

\section{Insert Fig 2}

Quite reasonably, a fast flipping motion, taking place through disrotation about the bonds connecting the upper aromatic ring and the nitrogen atoms, could possibly invert the curvature and keep the enantiomers in fast equilibrium. To verify such hypothesis we prepared the simple derivative 7 where the isopropyl group acts as diastereotopic NMR probe and observed that in its ${ }^{1} \mathrm{H}$ NMR spectrum the doublet corresponding to the methyl protons does not split even at $-40{ }^{\circ} \mathrm{C}$, Figure $3 .{ }^{17}$ 


\section{Insert Fig 3}

To exclude the possibility that the absence of splitting could be due to a small chemical shift difference between the resonances of the diastereotopic methyl groups, we synthesised compound $\mathbf{4}$ where the introduction of bulky groups in the imine region is expected to hinder the interconversion process. The variable temperature ${ }^{1} \mathrm{H}$ NMR spectra in $\mathrm{CD}_{3} \mathrm{OD}$ of compound 4 show indeed two nicely resolved doublets for the two isopropyl methyls at low temperatures, and only one doublet at higher temperatures (Figure 3). Coalescence is reached at $305 \mathrm{~K}$ and from this data an activation barrier of $15.7 \mathrm{kcal} \mathrm{mol}^{-1}$ is calculated. This observation confirms our idea that nonsymmetrically substituted uranyl-salophen complexes exist as a pair of enantiomers that interconvert into one another by a flipping motion that for compound 7 is so fast on the NMR timescale that it cannot be detected. The increase in bulkiness in the imine region hinders this motion and allows the observation of the phenomenon.

\section{Insert structures $\mathbf{7}$ and $\mathbf{8}$}

A further step in this direction was the synthesis of compound $\mathbf{8}$ in which, in addition to the phenyl substituent on the imine carbon, methyl groups where introduced on the phenylenediamine ring. These structural variations allowed us to measure an energy barrier for the interconversion of at least $21 \mathrm{kcal} \mathrm{mol}^{-1}$, since the two doublets of the isopropyl group in the $\left(\mathrm{CD}_{3}\right)_{2} \mathrm{SO}{ }^{1} \mathrm{H}$ NMR spectrum remain sharp even at $385 \mathrm{~K}$ (Figure 3). The precise determination of the height of the barrier was achieved using an (S)naproxen derivative of the uranyl-salophen $8{ }^{26}$ Isolation by crystallization of one of the two diastereoisomers of $\mathbf{9}$, that proved to be configurationally stable for at least one 
month at room temperature in the solid state, allowed us to measure the epimerization rate in chloroform solution and to estimate a value of $24.6 \mathrm{kcal} \mathrm{mol}^{-1}$ at $298 \mathrm{~K}$ for the barrier of the flipping motion. We believe that this value applies to a large variety of complexes of general structure 10, since the naproxen unit has a negligible influence on the epimerization process.

\section{Insert structures $\mathbf{9}$ and $\mathbf{1 0}$}

The inherent chirality of nonsymmetrical uranyl-salophen complexes arises upon complexation of the uranyl dication with achiral salophen ligands and originates from the fact that the bulky metal imposes a bent geometry to the salophen moiety so that no elements of symmetry are left. The peculiarity of these systems is that the uranyl ion is not a stereogenic centre in the strict sense, but with its bulkiness dissymmetrises the entire structure, imposing a curvature in an otherwise planar ligand. The use of the expression "inherently chiral" for such complexes was suggested to us by the implicit analogy with calix[4]arenes ${ }^{27}$ and fullerenes ${ }^{28}$ since in all these compounds chirality arises from the introduction of a curvature in an ideal planar structure that is devoid of symmetry axes in its bidimensional representation. ${ }^{29}$ Consequently in all the derivatives referred to as "inherently chiral" racemisation occurs, or would occur at least in principle, through inversion of the curvature.

Binding Properties. As already mentioned, uranyl-salophen complexes can bind donor groups by means of the fifth equatorial site still available after the coordination of the $\mathrm{UO}_{2}{ }^{2+}$ ion to the salophen ligand. In his pioneering work in the early nineteens, Reinhoudt and his coworkers showed that the solvent, that generally occupies this 
position, can be replaced by other electron rich molecules, such as urea, formamide, ${ }^{30}$ and anions. ${ }^{31}$ Among the neutral molecules that can be recognized and bound by uranylsalophen complexes there are ketones and enones. We found that compounds such as $\mathbf{1 1}$ show a good binding affinity toward a number of carbonyl compounds. In general, this affinity is larger than that showed by the unsubstituted uranyl-salophen parent compound and, in the majority of the cases, even of that of the corresponding symmetrically substituted one 12, Table 1. This behaviour can be explained by considering that, in addition to the primary binding force provided by the coordination of the carbonyl oxygen to the metal centre, there is a significant stabilization, in the range of 2-3 $\mathrm{kcal} \mathrm{mol}^{-1}$, resulting from van der Waals interactions of the guest with the aromatic walls. On the other hand, the strict complementarity requirements necessary to maximize these interactions could be hardly simultaneously achieved by both the aromatic cleft walls. As a consequence, in the case of the symmetrical complex some of the internuclear distances could lie in the repulsive region, diminishing the stability of the host-guest complexes with respect to the case of the corresponding non symmetrical one. Replacement of the phenyl group in $\mathbf{1 1}$ with larger aromatic unit, as in 13, results in stronger binding of large planar guests due to the extended contact surface between the receptor and the substrate, see footnote $b$ to Table 1 .

Insert structures 11, 12 and 13

Insert Table 1

URL: http:/mc.manuscriptcentral.com/tandf/gsch Email: suprachem@mail.cm.utexas.edu 
Uranyl-salophen complexes can also act as ditopic receptors towards ion pairs when endowed with flexible aromatic side arms, as $\mathbf{1 4}$, since the anion binds strongly to the hard Lewis acidic uranyl center, whereas the cation is interacting with the aromatic pendant arms through cation- $\pi$ interactions. We have indeed demonstrated recently such property $^{13 a}$ and shown that also the nonsymmetrically substituted compound $\mathbf{1 5}$ is an efficient binder for tetralkylammonium ${ }^{32}$ and alkali metal salts such as $\mathrm{CsCl}$, both in solution and in the solid state. ${ }^{12}$

\section{Insert structures $\mathbf{1 4}$ and $\mathbf{1 5}$}

Our finding that hindered non symmetrically substituted uranyl-salophen complexes exist as a pair of detectable enantiomers, prompted us to investigate their chiral recognition ability. ${ }^{13 \mathrm{~b}}$ To this purpose we synthesized compound 16, structurally analogous to $\mathbf{8}$, in which the binding site is properly shaped by introducing a phenyl and a methyl group on the two phenoxide rings in the ortho positions with respect to the oxygen atoms.

\section{Insert structure 16}

Preliminary screening of the chiral recognition ability of this receptor was carried out on its racemic mixture. To this purpose we developed a new NMR-based protocol to test their potentiality as enantioselective hosts. This protocol is fast and easy to use, and can be applied to racemic mixtures of receptors prior to resolution. It is a quite general method and can be applied whenever the diastereomeric adducts formed by the racemic 
host and the enantiomerically pure guest show even small but detectable chemical shift differences for the complexes. The selectivity values obtained in this way for receptor 16 toward $\alpha$-methylbenzylammine, 1-(2-naphthyl)ethylamine, methyl- $p$-tolylsulphoxide and N,N,N-trimethyl- $\alpha$-methylbenzylammonium chloride are shown in Table 2 . They are quite encouraging and demostrate, for the first time, that inherently chiral uranylsalophen complexes such as $\mathbf{1 6}$ can behave as enantioselective receptors.

\section{Insert Table 2}

Catalytic activity. Our interest in developing supramolecular catalysts based on the uranyl-salophen complexes $^{33}$ led us to consider the use of their non symmetrically substituted derivatives in the Diels-Alder addition of benzoquinone to 1,3cyclohexadiene. Indeed the combination of the Lewis acid-base coordination of the carbonyl oxygen to the metal together with the stabilizing van der Waals interactions of the substrate with the pendant aromatic side arm should represent a promising feature for catalysis. We should remind that an ideal catalyst is one in which a strong affinity toward the transition state is accompanied by a much lower interest for the reactant(s) and product(s). Artificial catalysts that meet these requirements are rare in the literature, nevertheless we discovered that $\mathbf{1 7}$ possesses such property and furthermore catalyses efficiently the above mentioned reaction whereas the parent unsubstituted complex $\mathbf{1 8}$ is completely inactive. The choice of a non symmetrically substituted complex was based on the idea that one face of the substrate, upon coordination to the uranyl, could establish favourable van der Waals interactions with the aromatic pendant arm, while the other can be easily approached by the diene (see scheme 3). We found that neither 
the reactant(s) nor the addition product give complexes of measurable stability with the uranyl-salophen catalyst, although the rate of addition of the quinone to the diene was significantly enhanced in the presence of it, whereas the corresponding unsubstituted parent compound was almost inactive. We interpreted these findings as follows. The aromatic side arm provides stabilization of the transition state through passive $\mathrm{e}^{34}$ binding. This contribution is clearly essential since the interaction of the uranyl centre with one of the benzoquinone oxygen, whose basicity increases during the activation process, is not sufficient per se to promote catalysis, as demonstrated by the fact that the parent complex is inactive.

\section{Insert Scheme 3}

Thus, the nonsymmetrically substituted uranyl-salophen complex $\mathbf{1 7}$ behaves as a supramolecular catalyst in that the side aromatic arm, promoting weak but significant van der Waals interactions with the substrate, becomes a protagonist in the catalysis.

Insert structures $\mathbf{1 7}$ and $\mathbf{1 8}$

Conclusion and Outlook. The present review covers the chemistry of non symmetrically substituted uranyl-salophen complexes with specific reference to their synthesis, binding properties, and catalytic activity. The possibility to modulate their structure within wide limits using properly substituted aldehydes and/or ketones as 
starting materials and our intriguing finding that they are inherently chiral provide new opportunities for their application. Nevertheless, as to optically active complexes some limitations remain concerning the preparative resolution of their racemic mixture. Unfortunately, unlike sterically unhindered uranyl-salophen complexes, the derivatives with bulky substituents in the imine region, introduced to block the flipping motion, do not tolerate any chromatographic treatment and easily dissociate under these conditions. We are currently working on this aspect, trying to obtain, through an alternative synthetic approach not implying heavy bulkiness in the imine region, configurationally stable, nonsymmetrically substituted uranyl-salophen complexes tolerant to chromatographic separation. ${ }^{35}$ Solving this problem will open the way to a large variety of optically pure chiral receptors with prospects of applications to enantioselective recognition and asymmetric catalysis.

Acknowledgements. We are indebted to Prof L. Mandolini for his inspiring guide and fruitful discussions. We acknowledge MIUR (COFIN 2003, Progetto Dispositivi Supramolecolari), COST Action D11 and D31 for financial contributions.

\section{References}

\footnotetext{
${ }^{1}$ Vigato P. A.;. Tamburini S. Coord. Chem. Rev., 2004, 248, 1717.

2 (a) Jacobsen E. N. in Comprehensive Organometallic Chemistry II,Vol. 12 (Eds.: E. W. Abel, F. G. A. Stone, G. Wilkinson), Pergamon, New York, 1995, pp. 1097 - 1135; (b) Yamada S. Coord. Chem. Rev., 1999, 190-192, 537.

${ }^{3}$ (a) Ohashi M.; Koshiyama T.; Ueno T.; Yanase M.; Fujii H.; Watanabe Y. Angew. Chem. Int. Ed., 2003, 42, 1005;(b) Mirkhani V.; Tangestaninejad S.; Moghadam M.; Moghbel M. Bioorg. Med. Chem., 2004, $12,4673$.

${ }^{4}$ Serrette A.; Carroll P. J.; Swager T. M. J. Am. Chem. Soc., 1992, 114, 1887.

${ }^{5}$ Zhang F.; Bai S.; Yap G. P. A.; Tarwade V.; Fox J. M. J. Am. Chem. Soc., 2005, 127, 10590.

${ }^{6}$ Di Bella S. Chem. Soc. Rev., 2001, 30, 355and references therein.

${ }^{7}$ (a) Pfeiffer P.; Hesse T.; Pfitzner H.; Scholl W.; Thielert H. J. Prakt. Chem., 1932, 217; (b) Bandoli G., Croatto D. A.; Vidali M.; Vigato P. A. J. Chem. Soc., Chem. Commun., 1971, 1330.

8 (a) Le Claiche L.; Vita C. Environ. Chem. Lett., 2006, 4, 45; (b) Sopo H.; Sviili J.; Valkonen A.; Sillanpää R. Polyhedron, 2006, 25, 1223; (c) Preetha C. R.; Gladis J. M.; Rao T. P. Environ. Sci.
} 
Technol., 2006, 40, 3070; (d) Bühl M.; Diss R.; Wipff G. J. Am. Chem. Soc., 2005, 127, 13506; (e) Gorden

A. E. V.; Xu J.; . Raymond K. N. Chem. Rev. 2003, 103, 4207 and references therein.

${ }^{9}$ Bandoli G.;. Clemente D. A J. Chem. Soc., Dalton Trans., 1975, 7, 612.

${ }^{10}$ Rudkevich D.M.; Huck W. T. S.; Van Veggel F. C. J. M.; Reinhoudt D. N.,"Metallomacrocycles and clefts: receptors for neutral molecules and anions" in Fabbrizzi L. and Poggi A. eds. Transition Metals in Supramolecular Chemistry NATO ASI Series (No. 448): Mathematical and Physical Science, 1994, Kluwer, Dordrecht, pp 329-349.

${ }^{11}$ (a) Van Doorn; A. R.; Verboom W.; Reinhoudt, D. N. "Molecular Recognition of Neutral Molecules by Synthetic Receptors“, in G. W. Gokel eds. Advances in Supramolecular Chemistry, 1993, JAI Press, Greenwich, vol. 3, pp 159; (b) van Axel Castelli, V.; Dalla Cort, A.; Mandolini, L.; Pinto, V.; Reinhoudt, D. N.; (c) Ribaudo F.; Sanna C.; Schiaffino L., Snellink-Ruël, B. H. M. Supramolecular Chem., 2002, 14, 211.

${ }^{12}$ Cametti, M.; Nissinen, M. ; Dalla Cort A.; Mandolini,L.; Rissanen K. J. Am. Chem. Soc., 2005, 127, 3831.

${ }^{13}$ (a) Cametti, M.; Nissinen, M. ; Dalla Cort A.; Mandolini,L.; Rissanen K. Chem. Commun., 2003, 2420; (b) Dalla Cort, A.; Miranda Murua, M. J. I.; Pasquini, C. ; Pons, M. ; Schiaffino L. Chem. Eur. J. 2004, 10,3301 .

${ }^{14}$ (a) van Axel Castelli, V.; Cacciapaglia, R.; Chiosis, G.; van Veggel, F. C. J. M.; Mandolini, L.; Reinhoudt, D. N. Inorg. Chim. Acta, 1996, 246, 181; (b) van Axel Castelli, V.; Dalla Cort, A. ; Mandolini, L. ; Reinhoudt, D. N.; Schiaffino, L. Eur. J. Org. Chem., 2003, 627 and references cited therein; (c) Dalla Cort, A.; Mandolini, L.; Schiaffino, L. Chem. Commun., 2005, 3867.

${ }^{15}$ Chrisstoffels, L. A. J.; De Jong, F.; Reinhoudt, D. N. Chem. Eur. J., 2000, 6, 1376.

${ }^{16}$ Antonisse, M. M.; Snellink- Ruël, B. H. M.;.Engbersen, J. F. J; Reinhoudt, D. N. J. Org. Chem., 1988, 63, 9776.

${ }^{17}$ Dalla Cort, A.; Mandolini, L.; Palmieri, G.; Pasquini, C.; Schiaffino L. Chem. Commun., 2003, 2178.

${ }^{18}$ Lopez, J.; Liang, S.; Bu, X. R. Tetrahedron Lett., 1998, 39, 4199.

${ }^{19}$ Daly, A. M.; Dalton, C. T.; Renehan, M. F.; Gilheany, D. G. Tetrahedron Letters, 1999, 40, 3617.

${ }^{20}$ E. J. Campbell, S. T. Nguyen Tetrahedron Lett., 2001, 42, 1221-1225.

${ }^{21}$ Danilova, T.; Rozenberg, V. I.; Vorontsov, E. V.; Starikova, Z. A.; Hopf, H. Tetrahedron: Asymmetry, 2003, 14, 1375.

${ }^{22}$ Renehan, M. F.; Schanz, H.-J.; McGarrigle, E. M.; Dalton, C. T.; Daly, A. M.; Gilheany, D. G. J. Mol. Cat. A: Chem, 2005, 231, 205.

${ }^{23}$ Boghaei, D. M.; Mohebi, S. Tetrahedron, 2002, 58, 5357.

${ }^{24}$ Kleij, A. W.; Tooke, D. M.; Spek, A. L.; Reek, J. N. H. Eur. J. Inorg. Chem., 2005, 4626.

${ }^{25}$ (a) van Staveren, C. J.; Fenton, D. E.; Reinhoudt, D. N.; van Eerden, J.; Harkema, S. J. Am. Chem. Soc., 1987, 109, 3456; (b) van Staveren, C. J.; van Eerden, J.; van Veggel, F. C. J. M.; Harkema, S.; Reinhoudt, D. N. J. Am. Chem. Soc., 1988, 110, 4994; (c) Reinhoudt, D. N.; den Hertog Jr., H. J. Bull. Soc. Chim. Belg.,1988, 97, 645; (d) van Doorn, A.R.; Schaafstra, R.; Bos, M.; Harkema, S.; van Eerden, J.; Verboom, W.; Reinhoudt, D. N. J. Org. Chem., 1991, 56, 6083; (e) van Doorn, A. R.; Verboom, W.; Harkema, S.; Reinhoudt, D. N. Synthesis, 1992, 119; (f) Rudkevich, D. M.; Stauthamer, W. P. R. V.; Verboom, W.; Engbersen, J. F. J.; Harkema, S.; Reinhoudt, D. N. J. Am. Chem. Soc., 1992, 114, 9671.

${ }^{26}$ Dalla Cort, A.; Mandolini, L.; Pasquini, C.; Schiaffino, L. Org. Lett., 2004, 6, 1697.

${ }^{27}$ Bohmer, V.; Kraft, D.; Tabatai, M. J. Inclusion Phenom. Mol. Recognit. Chem., 1994, 19, 17.

${ }^{28}$ Powell, W. H.; Cozzi, F.;. Moss, G. P; Thilgen, C.; Hwu, R. J.-R.; Yerin, A. Pure Appl. Chem., 2002, $74,629$.

${ }^{29}$ Dalla Cort, A.; L. Mandolini, L.; Pasquini, C.; Schiaffino, L. New. J. Chem., 2004, 1198.

${ }^{30}$ (a) van Doorn, A. R.; Schaafstra, R.; Bos, M.; Harkema, S.; van Eerden, J.; Verboom, W.; Reinhoudt, D. N. J. Org. Chem., 1991, 56, 6083.

31 (a) Rudkevich, D. M.; Stauthamer, W. P. R.; Verboom, W.; Engbersen, J. F. J.; Harkema, S.;

Reinhoudt, D. N. J. Am. Chem. Soc., 1992, 114, 9671; (b) Rudkevich, D. M.; Verboom, W.; Brozka, Z.; Palys, R. J.; Stauthamer, W. P. R.; Van Hummel, G. J.; Franken, S. M.; Harkema, S.; Engbersen, J. F. J.; Snellink- Ruël, B. H. M.; Reinhoudt, D. N. J. Am. Chem. Soc., 1994, 116, 4341.

${ }^{32}$ Cametti, M. Ph.D. Thesis.

${ }^{33}$ van Axel Castelli, V.; Dalla Cort, A.; Mandolini, L.; Reinhoudt, D. N. J. Am. Chem. Soc., 1998, 120, 12688.

${ }^{34}$ Kirby, A. J. Angew. Chem., Int. Ed. Engl., 1996, 35, 706.

${ }^{35}$ Dalla Cort, A.; Mandolini, L.; Pasquini, C.; Schiaffino, L. J. Org Chem., 2005, 70, 9814. 
${ }_{5}^{4}$ Table 1. Association constants $\left(\mathrm{K}, \mathrm{M}^{-1}\right)$ for complexes between uranyl salophen derivatives $\mathbf{2}, \mathbf{1 2}$, and $\mathbf{1 1}$ in $\mathrm{CHCl}_{3}$ at ${ }^{6} 25^{\circ} \mathrm{C}$ with selected carbonyl compounds. ${ }^{11 \mathrm{~b}}$

\begin{tabular}{lccc}
\hline & $\mathbf{2}$ & $\mathbf{1 2}$ & $\mathbf{1 1}$ \\
\hline cyclohexanone & $<3^{\mathrm{a}}$ & 140 & 260
\end{tabular}

3-thiophenylcyclopentanone

$<3 \quad 686$


2

${ }_{5}^{4}$ Table 2. Selectivity values, $\mathrm{S}^{\mathrm{a}}$, and corresponding diastereomeric excesses, de, at $25^{\circ} \mathrm{C}$, obtained for the 6enantioselective recognition of selected chiral guests by host $\mathbf{1 6 .}$

\section{7}

8

9

10

11

12

13

${ }_{23}^{22} \mathrm{~S}=\mathrm{K}_{2} / \mathrm{K}_{1}$, where $\mathrm{K}_{1}$ and $\mathrm{K}_{2}$ are the stability constants of the two diastereomeric complexes deriving from the association of the optically

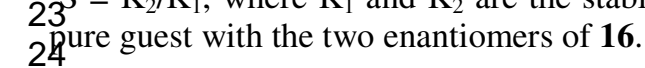

25
26
27
28
29
30
31
32
33
34
35
36
37
38
39
40
41
42
43
44
45
46
47
48
49
50
51
52
53
54
55
56
57
58
59
60




\section{${ }_{5}^{4}$ Captions to Figures and Schemes}

${ }_{10}^{9}$ Figure 1. Types of nonsymmetrically substituted metal-salophen complexes.

1 Şcheme 1. Synthesis of nonsymmetric $\mathrm{M}^{\mathrm{II}}$-salophen complex starting from non symmetric ortho-phenylenediamine 1 申recursors.

18 cheme 2. Synthesis of ligand 3 .

19

20

2Figure 2. Computer calculated structure of the uranyl-salophen complex $2 .{ }^{17}$ (Reproduced by permission of The 24 oyal Society of Chemistry)

2Figure 3. Temperature dependent ${ }^{1} \mathrm{H}$ NMR spectra of the methyl group signals of 7 (a, $300 \mathrm{MHz}$ in methanol- $\left.\mathrm{d}_{4}\right), 4$ $28 \mathrm{~b}, 300 \mathrm{MHz}$ in methanol- $\left.\mathrm{d}_{4}\right)$, and 8 (c, $300 \mathrm{MHz}$ in dimethylsulfoxide- $\left.\mathrm{d}_{6}\right){ }^{17}$ (Reproduced by permission of The 2Royal Society of Chemistry)

3\$cheme 3. Diels-Alder addition of benzoquinone to 1,3 -cyclohexadiene catalysed by $\mathbf{1 7 .}{ }^{14 c}$ (Reproduced by 35 ermission of The Royal Society of Chemistry) 


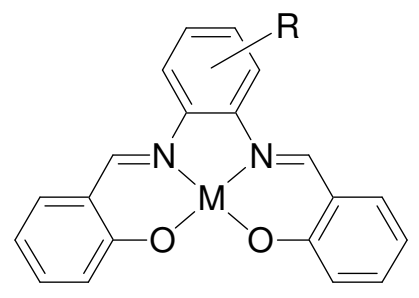

A

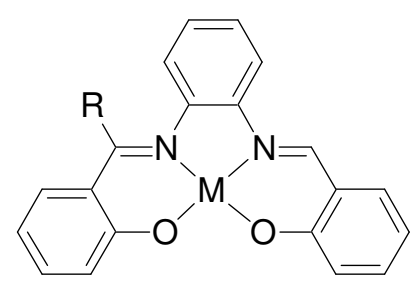

B

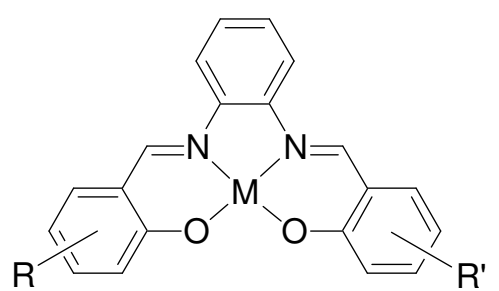

C 


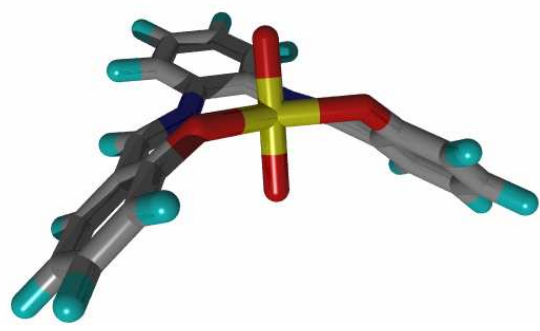




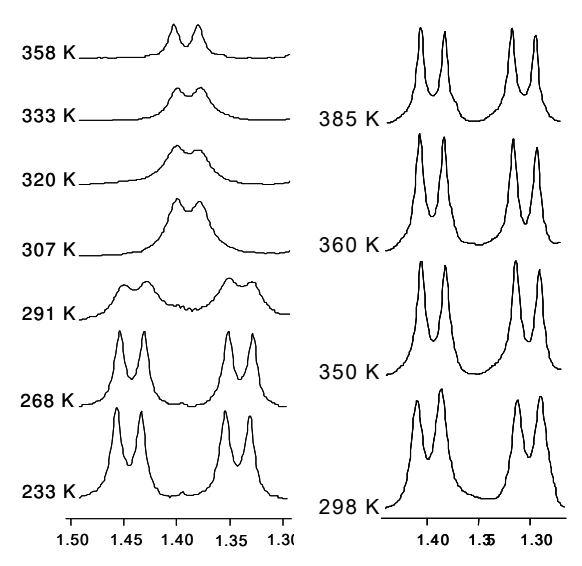

(b)

(c)

(b)

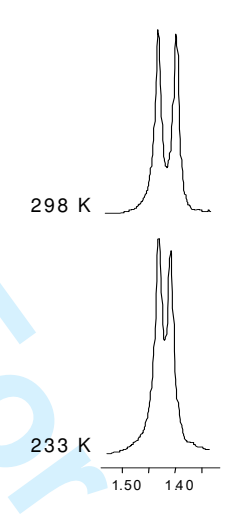

(a) 
7 Scheme 1

2<smiles>[R]c1[Y](C(=O)OC)c(N)c(N)c(N)c1[R]</smiles>

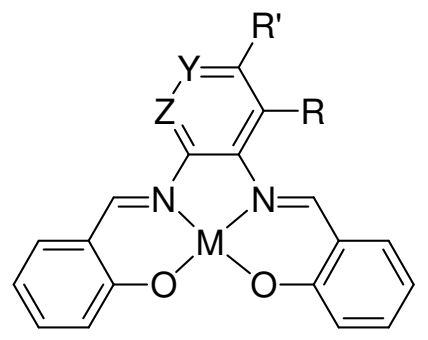

$$
\mathrm{Y}=\mathrm{C}, \mathrm{N}
$$$$
\mathrm{Z}=\mathrm{C}, \mathrm{N}
$$ 
7Scheme 2

8

9

10

11

12

13

14

15

17

18

19

20

21

22

23

24

25

26

27

28

29

30

31

32

33

34

35

36

37

38

39

40

41

42

43

44

45

46

47

48

49

50

51

52

53

54

55

56

57

58

59

60

URL: http:/mc.manuscriptcentral.com/tandf/gssch Email: suprachem@mail.cm.utexas.edu 

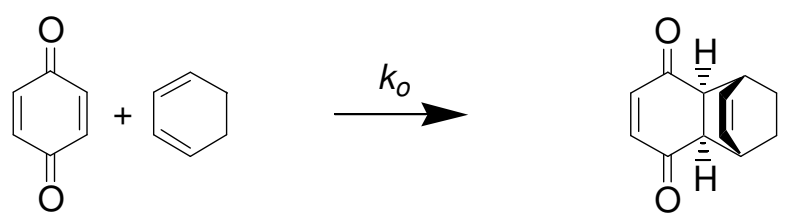


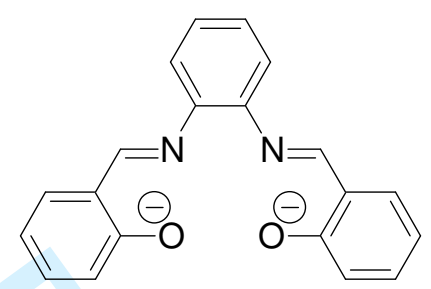

1

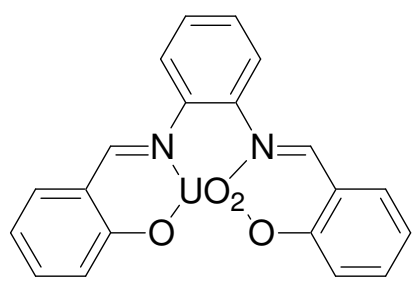

2

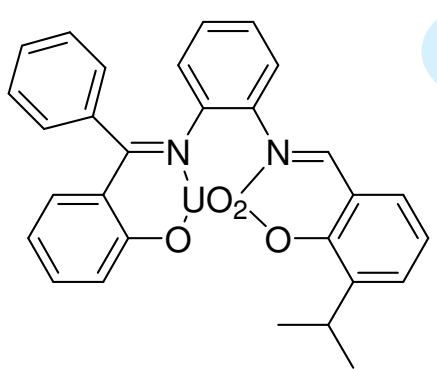

4

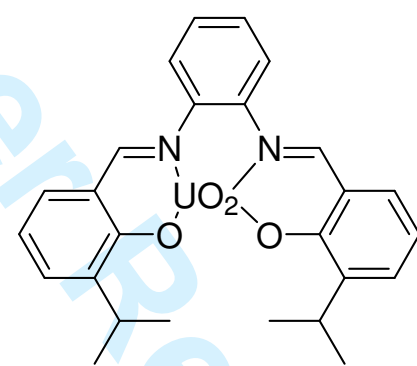

5<smiles>Nc1ccccc1N=C(c1ccccc1)c1ccccc1</smiles>

6

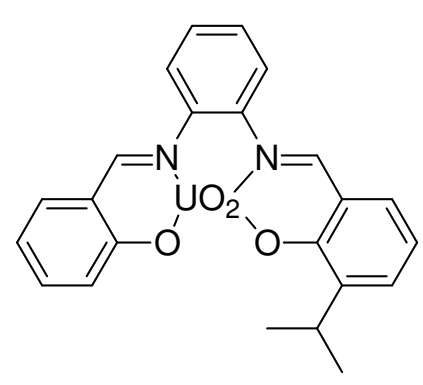

7

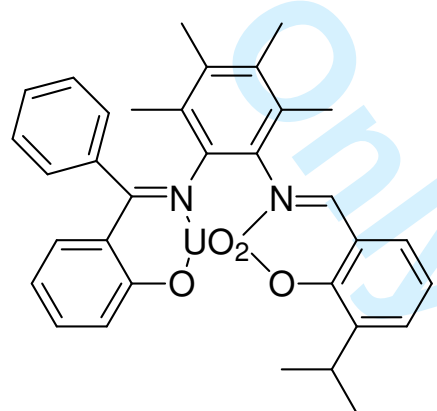

8 
Structures 9 and 10 6

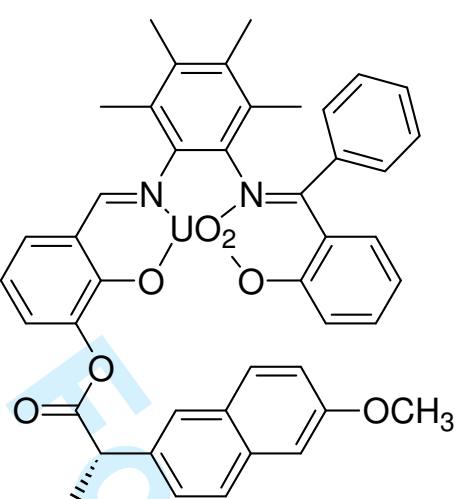

9

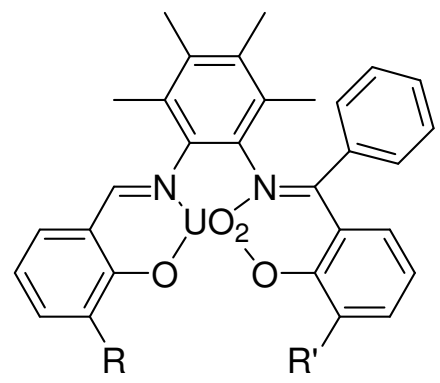

10

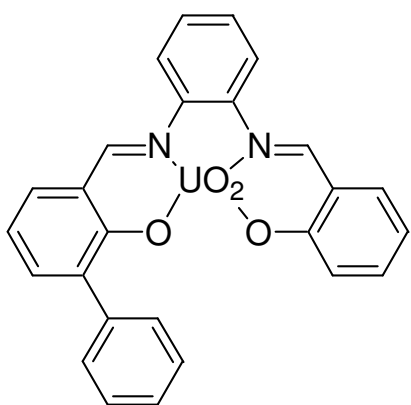

11

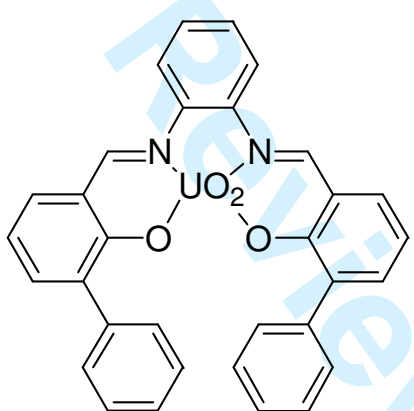

12

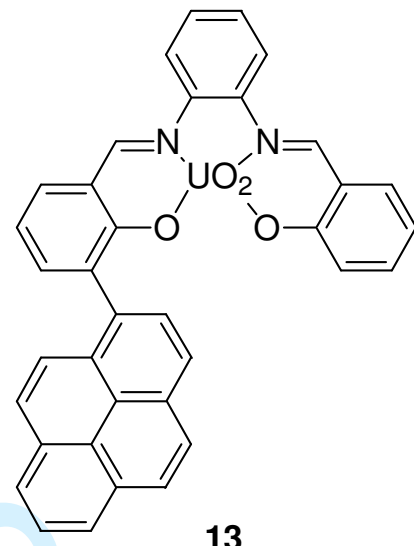

13 
7Structures 14 and 15

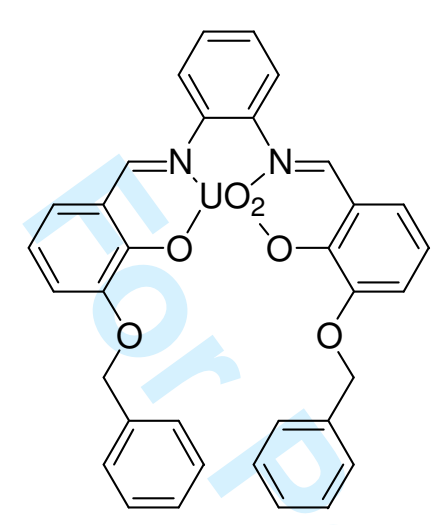

14

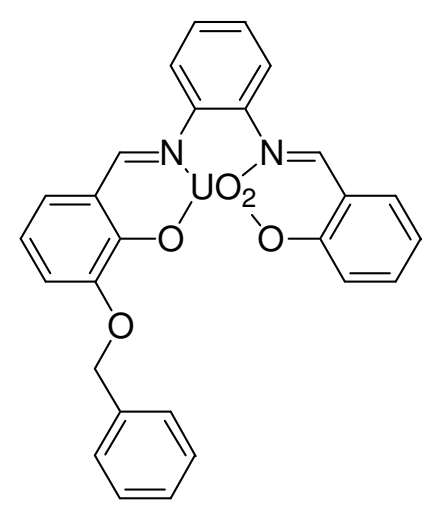

15

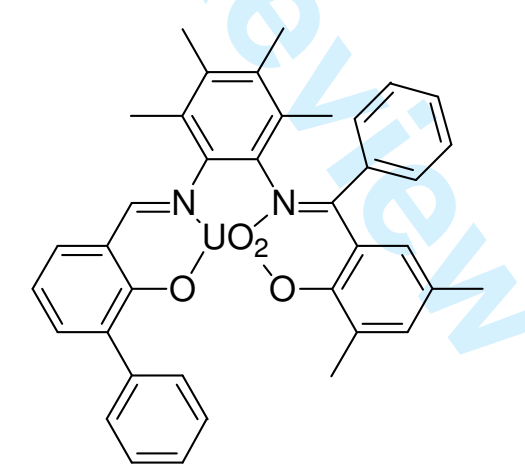

16

URL: http:/mc.manuscriptcentral.com/tandf/gsch Email: suprachem@mail.cm.utexas.edu 


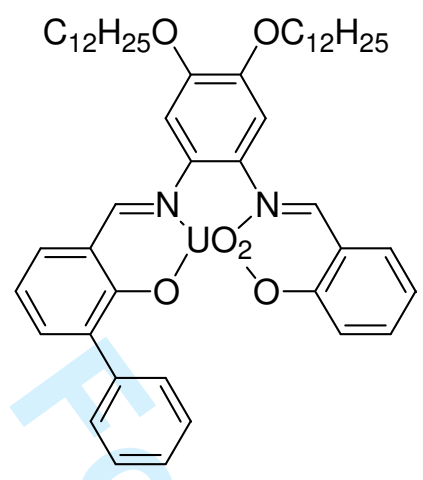

17

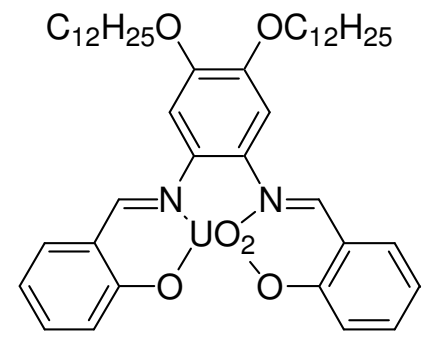

18 

Recognition and Catalysis

Antonella Dalla Cort*, Chiara Pasquini and Luca Schiaffino

Dipartimento di Chimica and IMC-CNR, Università La Sapienza, Box 34 - Roma 62, 00185 Roma, Italy 

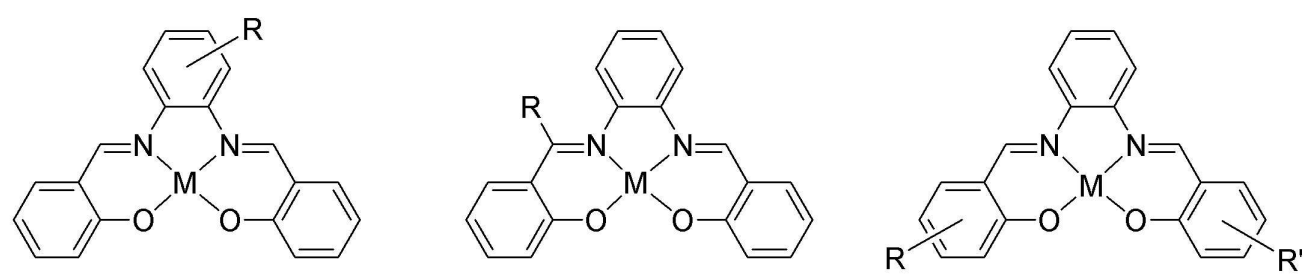


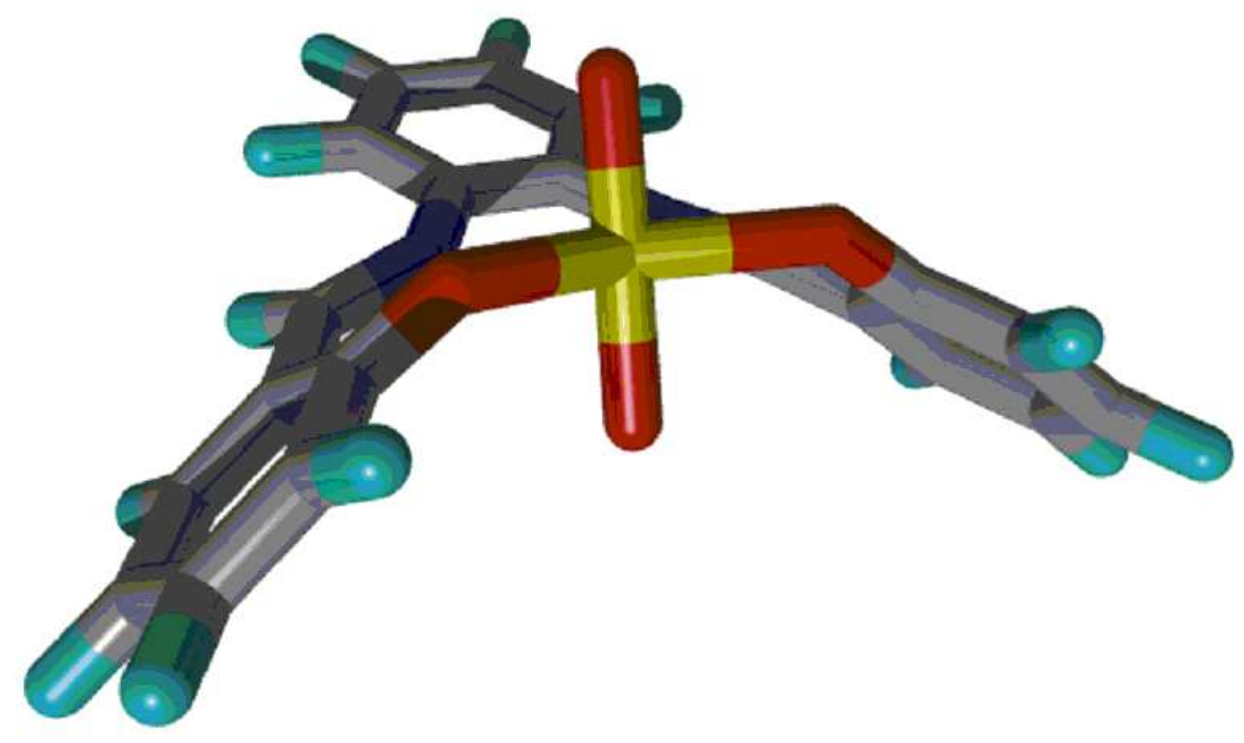

$57 \times 35 \mathrm{~mm}(360 \times 360$ DPI $)$

32

33

34

35

36

37

38

39

40

41

42

44

45

46

47

48

49

51

52

53

54

55

56 